\title{
Integration of Captive and Wild Studies to Estimate Egg and Larval Production of Fish Stocks
}

\author{
Yvan Lambert \\ Ministère des Pêches et des Océans, Institut Maurice-Lamontagne \\ C. P. 1000, Mont-Joli, Québec G5H 3Z4, Canada \\ Anders Thorsen \\ Institute of Marine Research, P. O. Box 1870 \\ Nordnes, N-5817 Bergen, Norway
}

\begin{abstract}
Experimental work on the reproduction of captive marine fish species provides the opportunity to improve our knowledge of the factors and mechanisms regulating reproduction of fish populations in natural environments. The integration of captive and wild studies can potentially be used to predict changes in the reproductive characteristics of fish populations in response to variations in specific environmental conditions in the wild. This dual approach can also be used to develop predictive models incorporating biological and environmental factors. However, differences in the acclimation to captivity, reproductive strategy, reproductive behaviour and susceptibility to stress may limit the extrapolation of laboratory work on different captive fish species to situations in the wild. For each species, some form of validation will be necessary to determine which of the different reproductive characteristics determined experimentally can be applied to wild fish. Wild fish should preferably be kept in captivity for limited periods of time prior to laboratory experiments and holding conditions should mimic environmental conditions as closely as possible. Natural food should be preferred to formulated feeds and the quantity of food should be adjusted to obtain growth, maturation and reproductive effort in the range observed for wild fish. Repeatability of experimental results should be evaluated by comparing the results of more than one experiment with the same experimental protocol and/or by using the same protocol in different laboratories.
\end{abstract}

Key words: cod, condition factor, eggs, fecundity, fertilization, fish, flatfish, marine, reproduction, tank experiments, wild stock, captive studies.

\section{Introduction}

Experiments with captive fish cannot reproduce conditions observed in the wild, but they can nevertheless provide tools to estimate and understand mechanisms causing variability in egg and larval production in wild populations. Design of experimental studies as well as constraints associated with species under study will determine our capacity to use the results of these captive fish studies to estimate the reproductive potential of wild stocks.

Methods used to study the reproduction of captive marine fishes can be very different. Thus, the possible applications of the results to wild fish populations will differ depending on species and methodology of study. Some form of species-related validation will be necessary in order to determine which of the different experimentally-determined reproductive parameters can be applied to wild fish.
This contribution presents species-specific approaches used to study the reproduction of marine fish in the laboratory. The reproductive strategy, husbandry conditions, manipulations of the fish, reproductive characteristics measured and the advantages and limitations associated with each approach are examined. This information is used to evaluate the potential applications of laboratory experiments to estimate the reproductive characteristics and reproductive potential of wild fish stocks.

\section{Species suitability to captivity and laboratory studies}

Most marine fish species used for laboratory experiments are determinate spawners (Murua and Saborido-Rey, 2003). Both total and batch spawners have been studied. However, studies on batch spawners require more elaborate logistics since each female has to be followed individually and very often for long periods of time. In these situations, experiments will generally be completed on a limited number 
of fish. For example, studies on the egg production of Atlantic cod (Gadus morhua), haddock (Melanogrammus aeglefinus), American plaice (Hippoglossoides platessoides) and yellowtail flounder (Pleuronectes ferrugineus) were typically conducted using 10 to 20 females per spawning season (Hislop et al., 1978; Kjesbu, 1989; Chambers and Waiwood, 1996; Kjesbu et al., 1996; Manning and Crim, 1998; Trippel, 1998; Nagler et al., 1999; Lambert and Dutil, 2000).

Factors to consider for laboratory experiments on reproduction include the method of capture and the behaviour of the selected fish species in captivity. The capture and transport of wild fish for laboratory experiments always induces some stress and mortality. Common methods of capture for marine fish include trawl, seine, hook and line, trap and SCUBA diving. These methods can induce injuries to the skin, mouth and jaws that can eventually lead to osmotic problems and infections. The depth of capture for physoclistic species (e.g. cod) can also induce injuries due to the expansion of gases as fish are brought to the surface. Rupture of the swimbladder, gas embolism and exopthalmia are some of the injuries that can result from depressurization (Bruesewitz et al., 1993). Fish must be captured early enough to let them adapt to captivity before commencing experiments. Acclimation periods between 1 and 4 months are often observed for wild fish brought to the laboratory (Dutil et al., 1992; Ma et al., 1998). However, fish have been caught several (6-12) months and even years before being used in some reproductive experiments (Manning and Crim, 1998; Trippel, 1998; Trippel et al., 1998; Morgan et al., 1999; Nagler et al., 1999; Lambert and Dutil, 2000). These longer acclimation periods prevent possible disruption of the maturation cycle due to the stress of capture and allow the manipulation of experimental conditions before the onset of maturation.

Many species adapt quickly and appear to behave normally in captivity. For example, wild cod captured with long lines or bottom trawl and brought to captivity in good condition quickly resume feeding, are resistant to disease and have good survival rates. Other species, such as winter flounder (Pseudopleuronectes americanus), can be less suited to captive conditions. Winter flounder broodstock can experience major losses associated with handling stress or due to fin or tail-rot diseases (Hoornbeek et al., 1982; Burton and Idler, 1987; Harmin and Crim, 1992), although such problems have not been mentioned elsewhere (Litvak, 1999). Finally, some species are less suited to laboratory experiments due to high mortality rates at capture. For example, spawner mortality of wild sole (Solea solea) can be high during the first month of captivity (Devauchelle et al., 1987). Losses of Atlantic herring (Clupea harengus) during the first month of captivity may range from a low of 10\% (Ma et al., 1998) to greater than $50 \%$ (A. Thorsen, unpubl. data) even when captured by purse seine and may be related to extensive scale loss. High sensitivity to changes in depth has prevented deepwater species such as redfish (Sebastes $s p$.) from being maintained in good condition in captivity. However, SCUBA techniques for capturing live specimens have now been developed (Larocque, 2000).

Difficulties associated with the capture of fish and/ or very long periods of acclimation to laboratory conditions can sometimes be circumvented by developing broodstocks from cultivated larvae or juvenile fish. It has been suggested that the effects of stress on broodstocks decline with each culture generation (Pankhurst and Van der Kraak, 1997). Laboratory experiments using fish hatched and raised in captivity have been conducted for some species (e.g. Kjesbu, 1989; Kjesbu et al., 1991; Bromley et al., 2000). However, domestication of fish may reduce the relevance of experiments designed to understand wild situations. For example, cod held under aquaculture conditions from the egg stage will usually attain much higher condition (i.e. fat reserves) and mature at a much younger age and smaller size than wild fish (Bergstad et al., 1987; Svåsand et al., 1996).

Other important aspects to consider for each individual species include maturation cycle, ovulation, spawning and behaviour in captivity. While most species appear capable of developing mature gonads in captivity, only a few will be able to spawn spontaneously in captivity (Crim and Wilson, 1998). Many species will have to be manually stripped of gametes or given hormonal injections to induce ovulation (Harmin and Crim, 1992; Larsson et al., 1997; Crim and Wilson, 1998). In some marine fishes, including flatfishes like American plaice and winter flounder (Harmin and Crim, 1992; Nagler et al., 1999) the absence of appropriate environmental cues or the presence of other stressors can prevent females with well-developed ovaries from ovulating. Species with more complex reproductive cycles are seldom used for laboratory experiments. Viviparous species like redfish (Sebastes sp.) which have distinct periods for copulation, sperm storage, fertilization, embryogenesis and larval extrusion have not yet been used extensively in laboratory studies. Some work has been done on Pacific coast redfish but these studies were limited to embryogenesis and larval de- 
velopment most probably because these fish do not reproduce naturally in tanks (Boehlert et al., 1986; Yamada and Kusakari, 1991). No signs of reproductive activity have been observed for broodstocks of Atlantic redfish (Sebastes fasciatus) kept in captivity for more than 2 years (Y. Lambert, unpubl. data). Nonetheless, some studies on the growth and survival of Atlantic redfish larvae have been realized, larvae near extrusion being relatively easy to obtain by stripping ripe females at sea (Laurel et al., 2001).

A large repertoire of sounds and behaviours within and between sexes have been observed during the reproduction of some gadoid species (Brawn, 1961; Hawkins et al., 1967; Hawkins and Rasmussen, 1978; Hutchings et al., 1999; Hawkins and Amorim, 2000; Bremner et al., 2002). Different behavioural acts leading to mating were associated with particular sounds in haddock (Hawkins and Amorim, 2000). A large repertoire of behavioural acts was also observed in Atlantic cod (Brawn, 1961; Hutchings et al., 1999), but sound production was less versatile than in haddock (Hawkins and Rasmussen, 1978). It was suggested that sounds and the sequence of behavioural acts associated with mating played a role in synchronizing the reproductive behaviour of each gender (Hawkins and Amorim, 2000). Mating behaviour also suggests that eggs and milt are released simultaneously and in close proximity (Hawkins and Amorim, 2000). Disruption of behaviour leading to mating in captive conditions could reduce reproductive success.

\section{Study limitations}

Besides acclimation and behaviour of fish species in captivity, experimental approaches are largely dictated by the reproductive characteristics under study. To our knowledge, no study has examined the complete sequence of reproductive characteristics from potential fecundity, realized fecundity and egg and larval characteristics and viability on the same individual fish. Most studies are restricted to the evaluation of some of these reproductive characteristics due to technical limitations. The absence of techniques to measure potential fecundity without killing fish has prevented the measurement of both potential and realized fecundity on the same individual female. However, methods combining ultrasonography to determine sex and gonad size (Mattson, 1991; Karlsen and Holm, 1994; Martin-Robichaud and Rommens, 2001) and biopsy samples of ovarian tissues to count oocytes (Bromley et al., 2000) could be developed. Nevertheless, information on the relationship between potential and realized fecundity has been obtained in experiments with groups of fish. For example, Kjesbu et al. (1991) sampled cod that had spawned different numbers of egg batches in order to obtain measures of realized fecundity and estimates of potential fecundity. Determination of the level of atresia for different groups of fish was also used to determine the relationship between potential and realized fecundity (Kjesbu et al., 1991; Ma et al., 1998). There are examples of studies where many of the relationships between realized fecundity, fertilization rate, egg characteristics and survival, hatching success and larval characteristics and viability were examined for individual females (Buckley et al., 1991; Marteinsdottir and Steinarsson, 1998; Nissling et al., 1998; Trippel, 1998; Nagler et al., 1999; Keckeis et al., 2000; Ouellet et al., 2001). However, studies on batch spawners are more complicated due to the amount of work and availability of experimental set-up needed to follow the different egg batches of several females.

\section{Protocols for studying reproduction}

Atlantic cod and haddock are batch spawning species that spawn on their own in captivity. They can produce between 2 and 20 egg batches during a period varying between 6 and 122 days (Hislop et al., 1978; Kjesbu, 1989; Chambers and Waiwood, 1996; Trippel, 1998; Trippel et al., 1998; Lambert and Dutil, 2000). Usually, male and female pairs are placed in spawning tanks and followed during the entire spawning period using collectors to retain the naturally fertilized, pelagic eggs. Volume of eggs, number of eggs spawned, proportion of eggs fertilized, egg size and egg dry weight and energy content are some of the common measures taken. Egg subsamples from different batches are used to monitor egg development, hatching success and larval size in different experimental conditions. Eggs can be incubated in groups or individually. A more complete description of methods and measurements is given by Thorsen et al. (2003). Some studies on eggs and larvae also used communal spawning tanks containing larger numbers of fish (Pepin et al., 1997; Buckley et al., 2000). However, the communal broodstock approach is restrictive when examining individual maternal effects on the size and quality of eggs (Trippel et al., 1998).

Batch spawning flatfishes, such as American plaice, turbot (Scophthalmus maximus), yellowtail flounder and Atlantic halibut (Hippoglossus hippoglossus) have to be repeatedly stripped of gametes throughout the spawning season (McEvoy (Barton), 1984; Norberg et al., 1991; Manning and Crim, 1998; Nagler et al., 1999). These species release batches 
of eggs every few days during a spawning period that can extend for 46 days. Fish are individually marked and examined for ovulation. Females with swollen abdomens are gently squeezed and then stripped if eggs are expelled. Eggs are fertilized by mixing with semen collected from mature males. Eggs of winter flounder are stripped as a single batch and are negatively buoyant and adhesive. Diatomaceous earth is currently used to prevent adhesive eggs from clumping (Buckley et al., 1990; Litvak, 1999) but may damage eggs due to sharp edges on the particles (Litvak, 1999). When collecting eggs by hand stripping, care must be taken to avoid contamination by urine, feces and seawater (Dreanno et al., 1998; Nagler et al., 1999). Other flatfish species can potentially spawn on their own in captivity (Smith et al., 1999), although reproductive output may be low (Houghton et al., 1985; Devauchelle et al., 1987).

Different approaches have been used to study egg and larval stages of marine fish species in captivity. In many experiments, eggs and larvae were obtained from fish that were caught in the wild and acclimated to laboratory conditions (Kjesbu et al., 1991; Chambers and Waiwood, 1996; Trippel, 1998; Lambert and Dutil, 2000; Ouellet et al, 2001) or from fish that were reared in the laboratory from egg to adult stage (Kjesbu et al., 1996; Bromley et al., 2000). Experiments on egg and larval stages have also been conducted on fish that matured in the wild. Spawning female herring have been collected at sea and quickly transported to the laboratory, where the eggs were stripped and fertilized (Laine and Rajasilta, 1999). Eggs stripped from spawning female cod captured at sea were fertilized and kept on board ship for 2-3 days before being transported to the laboratory for experiments (Marteinsdottir and Steinarsson, 1998). Finally, laboratory experiments on egg and larval stages have been conducted on fertilized eggs collected directly at sea with plankton samplers (Riveiro et al., 2000). Methods and measures to determine the quantity and quality of eggs and larvae produced by captive marine fish are reviewed by Thorsen et al. (2003).

\section{Comparison of field and laboratory measurements}

Potential fecundity can be accurately measured in both field and captive conditions (Bagenal, 1978; Thorsen and Kjesbu, 2001; Murua et al., 2003). Comparisons of the results obtained in both situations can then be used to validate the use of laboratory experiments to improve and understand the variability of fecundity estimates in the wild. Nevertheless, some precautions must be taken before extrapolating labora- tory results to field situations. Husbandry conditions may produce results that are not in the range observed in wild fish. For example, captive cod in the study of Kjesbu et al. (1991) had higher condition factors and potential fecundities than wild cod. Captive cod fed different rations in the laboratory had condition factors between 1.1 and 1.8 with potential fecundities between 2 and 5.3 million eggs (fecundity for a standard $60 \mathrm{~cm}$ female). A wild cod of the same standard size had a condition factor of about 1 and a potential fecundity of 1.5 million. The extrapolation of results to wild cod, which generally exhibit lower condition factors and potential fecundities, has to be validated before derived equations are used to estimate the potential fecundity in wild populations. Long delays between capture and the observation of regular spawning in sole (Devauchelle et al., 1987) may also indicate that laboratory determinations of potential fecundity are not comparable to field situations at least during the early years of captivity.

Direct measurements of realized fecundity may not be obtainable for wild fish (Lambert et al., 2003) and for batch spawners like cod and haddock can only be obtained using tanks equipped with collectors (Hislop et al., 1978; Kjesbu, 1989; Trippel, 1998; Trippel et al., 1998; Lambert and Dutil, 2000; Thorsen et al., 2003). Stripping of females may underestimate realized fecundity because manipulation during stripping and/or the timing of stripping in relation to ovulation time may result in the incomplete recovery of ovulated eggs (Buckley et al., 1991; Norberg et al., 1991). Potential fecundity of wild and captive fish appears to overestimate realized fecundity (Bromley et al., 2000). Realized fecundity of American plaice in the laboratory was considerably lower than the potential fecundity in the wild (Nagler et al., 1999), perhaps due to atresia and ovulatory failure. Laboratory experiments with cod indicated that realized fecundity was between 20 and $80 \%$ of the potential fecundity depending on the nutritional status of the fish (Kjesbu et al., 1991). Oocyte atresia has even been associated with spawning failure in this species (Rideout et al., 2000).

Determination of the level of atresia has been used as an indirect method of estimation of realized fecundity (Ma et al., 1998). Many laboratory studies have examined the process of ovarian atresia and provided estimates of rates of atresia and duration of atretic follicles (Hunter and Macewicz, 1985; Kjesbu et al., 1991; Ma et al., 1998; Witthames et al., 2000). The prevalence of atresia in sole from the Channel, the North Sea and the Irish Sea was also used to estimate realized 
fecundity in the field (Witthames and Walker, 1995). Measurements of atresia in the laboratory and in the field could possibly be integrated to estimate the proportion of the potential fecundity in the wild that will effectively be realized. For example, a calibration using the atretic condition of the ovary of captive and wild northern anchovy (Engraulis mordax) was used to assess the reproductive state of this fish along the coast of California (Hunter and Macewicz, 1985).

Information on egg and larval characteristics (size, weight, energy, biochemical composition, etc.) has been obtained in the laboratory and in the wild (reviewed by Lambert et al., 2003). However, most of the information on the relationship between egg and larval characteristics and their subsequent survival has been obtained with experiments on captive fish (Lambert et al., 2003). Large variations in egg and larval traits, such as fertilization rate, egg survival, hatching rate and larval survival have been observed within and between studies (Manning and Crim, 1998; Trippel et al., 1998; Ouellet et al., 2001; Watanabe et al., 2001; Lambert et al., 2003). Greater variation in egg viability and fertilization rates seem to be observed in species that do not spawn naturally in captivity. In American plaice, the mean percentages of viable and fertilized eggs were $44.7 \%(11-71 \%)$ and $13.7 \%(0.2-49 \%)$, respectively (Nagler et al., 1999). Viable eggs were defined as those having a distinct perivitelline space but no blastula formation, indicating that they were not fertilized. The number of larvae that hatched varied widely with a mean hatch success of $23 \%$ (Nagler et al., 1999). Fertilization rates between $51 \%$ and $60 \%$ were observed for groups of female sole that spawned naturally (Houghton et al., 1985; Devauchelle et al., 1987). Higher egg quality of naturally spawning fish as opposed to hand-stripped fish, has been observed in turbot due to reduced stress and risk of physical damage (Bromley et al., 1986). Natural spawning also has been reported to produce larger numbers of viable embryos than hormone-induced spawning and is less labour intensive and time consuming (Watanabe et al., 2001). Proper timing of stripping in relation to ovulation markedly influences egg quality, fertilization and hatching rates (Hirose et al., 1977). Stripping can disturb the ovulation process (Watanabe et al., 2001) and overripening can cause rapid loss in egg viability. In turbot, hatching rates up to $97 \%$ observed in freshly ovulated eggs declined to $0 \%$ after 1 day of retention in the lumen of the ovary (McEvoy (Barton), 1984). Likewise, the fertilization rate of female snapper (Parus auratus) decreased to less than $50 \%$ after $6 \mathrm{hr}$ of being retained in the oviduct (Hobby and Pankhurst, 1997).
The variability in egg size, egg dry weight, fertilization rate, and hatching success may be inherent to laboratory work. However, since little is known of spawning events in the wild, it is possible that the same variability is present in the wild (Bromley et al., 1986; Manning and Crim, 1998).

\section{Integration of experiments with captive fish}

Influences of captivity on reproduction. The capture of wild fish for experiments on reproduction as well as routine husbandry procedures such as handling and confinement can be stressful to fish and may affect reproduction (Pankhurst and Van der Kraak, 1997). Stress can affect oocyte development and quality, as well as egg and larval survival and development. Increased amounts of atresia were observed in vitellogenic oocytes of wild mature female red gurnard (Chelidonichthys kumu) kept in tanks, indicating that capture and confinement stress can negatively affect their reproduction (Clearwater and Pankhurst, 1997). An increased incidence of ovarian atresia in wild and hatchery-reared snapper (Pagrus auratus) indicated that this species was highly susceptible to stress-induced impairment of reproduction (Cleary et al., 2000). The lower incidence of atresia in hatchery-reared fish, however, indicated that hatchery fish were less susceptible to stress than wild fish. Stress induced by confinement also resulted in the production of smaller eggs in rainbow trout (Oncorhynchus mykiss) and a lower survival of the progeny occurred of stressed rainbow and brown trout (Salmo trutta) compared to unstressed fish (Campbell et al., 1994). Chronic stress produced by chasing and capturing fish three times a week caused cod to produce greater numbers of abnormal larvae, but did not affect egg production, fertilization rate, hatching success or time to starvation of larvae (Morgan et al., 1999). Extensive, but careful handling of Atlantic halibut showed no effect of manipulation on ovarian growth and ovulatory cycle (Norberg et al., 1991). Likewise, handling stress produced by anaesthetising and injecting fathead minnow (Pimephales promelas) on three occasions before reproduction did not influence fecundity and hatching success (Kahl et al., 2001). Adverse effects of handling may be reduced after several generations of culturing (Kahl et al., 2001) and may differ between individuals (Norberg et al., 1991).

Many physiological, haematological and physical condition indicators are used to monitor stress in fish. Blood glucose, cortisol, haemoglobin, hematocrit, white blood cells, ionic composition and condition indices are some of the variables commonly used as indicators 
of stress (Morgan and Iwama, 1997). Abnormal behaviour, changes in colouration, and lesions to skin and fins also represent signs of stress and/or disease. Experiments with captive fish should include the measurement of some of these indicators. Experiments designed to measure responses to different levels of stress in the laboratory can be used to evaluate the susceptibility of different fish species to stress-induced impairment of reproduction. This information is important in extrapolating results on reproductive investment of captive fish to field situations.

Experimental conditions. Laboratory experiments designed to understand the reproduction of fish in natural environments should preferably use wild fish kept in captivity for limited periods of time. Fish should be captured before the onset of maturation to prevent the possible stress-related disruption of the maturation cycle. The use of domesticated fish should be avoided if possible. Selective breeding can lead to important differences in stress resistance, growth and reproduction between domesticated and wild fish (Pankhurst and Van der Kraak, 1997; Pottinger and Pickering, 1997).

Laboratory conditions never entirely mirror a fish's natural environment. However, holding conditions should mimic as closely as possible environmental conditions. Feeding schedule, ration and diet are of vital importance. Natural prey are preferred to formulated feeds and the quantity of food should be determined in order to obtain growth, maturation and reproductive effort in the range observed for wild fish. For example, cod fed on diets with a high lipid energy: total energy ratio will develop enlarged fatty livers which are considered abnormal for natural populations (Jobling, 1988). In many studies, feeding is stopped at the beginning of spawning (Kjesbu, 1989; Lambert and Dutil, 2000). This can ease manipulations and/or prevent problems with contamination (Manning and Crim, 1998). In many species, fish do not usually eat during the spawning period (Fordham and Trippel, 1999) but this may not be the case for all species (Hislop, 1975; Hislop et al., 1978) or possibly for all conditions of a given species.

Sampling spawning females at sea can represent an alternative method to study and integrate egg and larval characteristics and survival measured in the laboratory to field situations, particularly for species that exhibit problems in acclimation to captivity. By sampling spawning female herring over a series of years at sea and incubating eggs, Laine and Rajasilta (1999) were able to determine egg characteristics and viability in controlled conditions for females subjected to variations in environmental conditions during maturation. However, the results obtained with the eggs of batch spawners collected at sea could be more difficult to interpret if batch number, which influences egg characteristics (Hislop, 1975; Hislop et al., 1978; Hinckley, 1990; McEvoy and McEvoy, 1992; Trippel, 1998; Ouellet et al., 2001), is difficult to identify.

Experimental studies on egg and larval quality and survival have produced variable results. Handling stress during the course of reproduction, stripping, over-ripening, contamination of eggs, and infections caused by bacteria, protozoa and fungi can have marked effects on fertilization rates, hatch rates and survival (McEvoy (Barton), 1984; Manning and Crim, 1998; Nagler et al., 1999). Nonetheless, many studies consider that this approach provides valid information on the reproductive performance of species in natural environments (Buckley et al., 1991; Marteinsdottir and Steinarsson, 1998; Trippel, 1998; Laine and Rajasilta, 1999). Other studies admit to some reservations in extrapolating laboratory results to the wild. Benoît and Pepin (1999) hesitated to extrapolate hatching success results in yellowtail flounder from small static rearing containers to pelagic eggs in the wild. However, their results suggested that the pattern of hatching success would vary across temperatures encountered in the wild.

It is very important to ensure the repeatability of results from experimental work before extrapolation to field situations, especially for measurements of egg and larval quality and viability. Repeatability of experiments can be evaluated by comparing the results of more than one experiment with the same experimental protocol. Identical protocols and fish from the same stocks or eggs from the same females can be used in different laboratories to corroborate results.

Utility of laboratory studies. The determination of the reproductive potential of fish populations is important in analysing population dynamics. In that context, more precise estimation of egg production, not only in numbers but also in quality, is warranted. The integration of results on captive fish provides an opportunity by which estimation of the reproductive potential of fish populations may be improved. Laboratory work can greatly increase our knowledge of the factors and mechanisms regulating some aspects of reproduction, especially realized fecundity and egg and larval quality and viability. These reproductive char- 
acteristics are not always easy to measure in the wild. The integration of captive and wild studies could be used to predict changes in egg production in response to changes in specific environmental conditions in the wild and to develop predictive models incorporating biological and environmental factors.

However, the application of experimental work on captive fish to situations in the wild is not straightforward. Some restrictions associated with the ability of fish species to adapt to captive conditions, their reproductive behaviour, and the experimental manipulations employed may limit the use of laboratory findings. Careful validation and calibration are necessary before extrapolating the results of experiments on captive fish to the wild.

\section{Acknowledgements}

We greatly appreciate the comments and suggestions made by two referees that led to improvement of an earlier manuscript draft.

\section{References}

BAGENAL, T. B. 1978. Method for assessment of fish production in fresh waters. Blackwell Scientific Publications, London. 365 p.

BENOÎT, H. P., and P. PEPIN. 1999. Interaction of rearing temperature and maternal influence on egg development rates and larval size at hatch in yellowtail flounder (Pleuronectes ferrugineus). Can. J. Fish. Aquat. Sci., 56: 785-794.

BERGSTAD, O. A., T. JÖRGENSEN, and O. DRAGESUND. 1987. Life history and ecology of the gadoid resources of the Barents Sea. Fish. Res., 5: 119-161.

BOEHLERT, G. W., M. KUSAKARI, M. SHIMIZU, and J. YAMADA. 1986. Energetics during embryonic development in kurosoi, Sebastes schlegeli Hilgendorf. J. Exp. Mar. Biol. Ecol., 101: 239-256.

BRAWN, V. M. 1961. Reproductive behaviour of the cod (Gadus callarias L.). Behaviour, 18: 177-198.

BREMNER, A. M., E. A. TRIPPEL, and J. A. TERHUNE. 2002. Sound production of adult haddock (Melanogrammus aeglefinus) in isolation, pairs and trios. Environ. Biol. Fish., 65: 359-362.

BROMLEY, P. J., C. RAVIER, and P. R. WITTHAMES. 2000. The influence of feeding regime on sexual maturation, fecundity and atresia in first-time spawning turbot. J. Fish. Biol., 56: 264-278.

BROMLEY, P. J., P. A. SYKES, and B. R. HOWELL. 1986. Egg production of turbot (Scophthalmus maximus L.) spawning in tank conditions. Aquaculture, 53: 287-293.

BRUESEWITZ, R. E., D. W. COBLE, and F. COPES. 1993. Effects of deflating the expanded swim bladder on survival of burbot. N. Am. J. Fish. Manage., 13: 346-348.
BUCKLEY, L. J., T. M. BRADLEY, and J. ALLENGUILMETTE. 2000. Production, quality, and low temperature incubation of eggs of Atlantic cod Gadus morhua and haddock Melanogrammus aeglefinus in captivity. J. World Aquacult. Soc., 31: 22-29.

BUCKLEY, L. J., A. S. SMIGIELSKI, T. A. HALAVIK, E. M. CALDARONE, B. R. BURNS, and G. C. LAURENCE. 1991. Winter flounder Pseudo-pleuronectes americanus reproductive success. II. Effects of spawning time and female size on size, composition and viability of eggs and larvae. Mar. Ecol. Prog. Ser., 74: 125-135.

BUCKLEY, L. J., A. S. SMIGIELSKI, T. A. HALAVIK, and G. C. LAURENCE. 1990. Effects of water temperature on size and biochemical composition of winter flounder Pseudopleuronectes americanus at hatching and feeding initiation. Fish. Bull. U.S., 88: 419-428.

BURTON, M. P., and D. R. IDLER. 1987. An experimental investigation of the non-reproductive, post-mature state in winter flounder. J. Fish. Biol., 30: 643-650.

CAMPBELl, P. M., T. G. POTTINGER, and J. P. SUMPTER. 1994. Preliminary evidence that chronic confinement stress reduces the quality of gametes produced by brown and rainbow trout. Aquaculture, 120: $151-169$.

CHAMBERS, R. C., and K. G. WAIWOOD. 1996. Maternal and seasonal differences in egg sizes and spawning characteristics of captive Atlantic cod, Gadus morhua. Can. J. Fish. Aquat. Sci., 53: 1986-2003.

CLEARWATER, S. J., and N. W. PANKHURST. 1997. The response to capture and confinement stress of plasma cortisol, plasma sex steroids and vitellogenic oocytes in the marine teleost, red gurnard. J. Fish. Biol., 50: 429-441.

CLEARY, J. J., N. W. PANKHURST, and S. C. BATTAGLENE. 2000. The effect of capture and handling stress on plasma steroid levels and gonadal condition in wild and farmed snapper Pagrus auratus (Sparidae). J. World Aquacult. Soc., 31: 558-562.

CRIM, L. W., and C. E. WILSON. 1998. Optimizing broodstock management technologies. Bull. Aquacult. Assoc. Can., 98-3: 9-13.

DEVAUCHELLE, N., J. C. ALEXANDRE, N. LE CORRE, and Y. LETTY. 1987. Spawning of sole (Solea solea) in captivity. Aquaculture, 66: 125-147.

DREANNO, C., M. SUQUET, E. DESBRUYERES, J. COSSON, H. LE DELLIOU, and R. BILLARD. 1998. Effect of urine on semen quality in turbot (Psetta maxima). Aquaculture, 169: 247-262.

DUTIL, J. D., J. MUNRO, C. AUDET, and M. BESNER. 1992. Seasonal variation in the physiological response of Atlantic cod (Gadus morhua) to low salinity. Can. J. Fish. Aquat. Sci., 49: 1149-1156.

FORDHAM, S. E., and E. A. TRIPPEL. 1999. Feeding behaviour of cod (Gadus morhua) in relation to spawning. J. Appl. Ichthyol., 15: 1-9.

HARMIN, S. A., and L. W. CRIM. 1992. Gonadotropic hormone-releasing hormone analog (GnRH-A) induced ovulation and spawning in female winter flounder, Pseudopleuronectes americanus (Walbaum). Aquaculture, 104: 375-390. 
HAWKINS, A. D., and M. C. P. AMORIM. 2000. Spawning sounds of the male haddock, Melanogrammus aeglefinus. Environ. Biol. Fish., 59: 29-41.

HAWKINS, A. D., C. J. CHAPMAN, and D. Y. SYMONDS. 1967. Spawning of haddock in captivity. Nature, 215: 923-925.

HAWKINS, A. D., and K. J. RASMUSSEN. 1978. The calls of gadoid fish. J. Mar. Biol. Assoc. U.K., 58: 891-911.

HINCKLEY, S. 1990. Variation of egg size of walleye pollock Theragra chalcogramma with a preliminary examination of the effect of egg size on larval size. Fish. Bull. U.S., 88: 471-483.

HIROSE, K., R. ISHIDA, and K. SAKAI. 1977. Induced ovulation of ayu using human chorionic gonadotropin (HCG), with special reference to changes in several characteristics of eggs retained in the body cavity after ovulation. Bull. Jap. Soc. Sci. Fish., 43: 409-416.

HISLOP, J. R. G. 1975. The breeding and growth of whiting, Merlangus merlangus in captivity. J. Cons. Int. Explor. Mer, 36: 119-127.

HISLOP, J. R. G., A. P. ROBB, and J. A. GAULD. 1978. Observations on effects of feeding level on growth and reproduction in haddock, Melanogrammus aeglefinus (L.) in captivity. J. Fish. Biol., 13: 85-98.

HOBBY, A. C., and N. W. PANKHURST. 1997. Postovulatory egg viability in the snapper Pagrus auratus (Sparidae). Mar. Freshwat. Res., 48: 385-389.

HOORNBEEK, F. K., P. J. SAWYER, and E. S. SAWYER. 1982. Growth of winter flounder (Pseudopleuronectes americanus) and smooth flounder (Liopsetta putnami) in heated and unheated water. Aquaculture, 28: $363-373$.

HOUGHTON, R. G., J. M. LAST, and P. J. BROMLEY. 1985. Fecundity and egg size of sole (Solea solea (L.)) spawning in captivity. J. Cons. Int. Explor. Mer, 42: $162-165$.

HUNTER, J. R., and B. J. MACEWICZ. 1985. Rates of atresia in the ovary of captive and wild northern anchovy, Engraulis mordax. Fish. Bull. U.S., 83: 119-136.

HUTCHINGS, J. A., T. D. BISHOP, and C. R. MCGREGORSHAW. 1999. Spawning behaviour of Atlantic cod, Gadus morhua: Evidence of mate competition and mate choice in a broadcast spawner. Can. J. Fish. Aquat. Sci., 56: $97-104$.

JOBLING, M. 1988. A review of the physiological and nutritional energetics of cod, Gadus morhua L., with particular reference to growth under farmed conditions. Aquaculture, 70: 1-19.

KAHL, M. D., K. M. JENSEN, J. J. KORTE, and G. T. ANKLEY. 2001. Effects of handling on endocrinology and reproductive performance of the fathead minnow. J. Fish. Biol., 59: 515-523.

KARLSEN, O., and J. C. HOLM. 1994. Ultrasonography, a non-invasive method for sex determination in cod (Gadus morhua). J. Fish Biol., 44: 965-971.

KECKEIS, H., E. BAUER-NEMESCHKAL, V. V. MENSHUTKIN, H. L. NEMESCHKAL, and E. KAMLER. 2000. Effects of female attributes and egg properties on offspring viability in a rheophilic cyprinid, Chondrostoma nasus. Can. J. Fish. Aquat. Sci., 57: 789-796.

KJESBU, O. S. 1989. The spawning activity of cod, Gadus morhua L. J. Fish Biol., 34: 195-206.

KJESBU, O. S., J. KLUNGSØYR, H. KRYVI, P. R. WITTHAMES, and M. GREER WALKER. 1991. Fecundity, atresia, and egg size of captive Atlantic cod (Gadus morhua) in relation to proximate body composition. Can. J. Fish. Aquat. Sci., 48: 2333-2343.

KJESBU, O. S., P. SOLEMDAL, P. BRATLAND, and M. FONN. 1996. Variation in annual egg production in individual captive Atlantic cod (Gadus morhua). Can. J. Fish. Aquat. Sci., 53: 610-620.

LAINE, P., and M. RAJASILTA. 1999. The hatching success of Baltic herring eggs and its relation to female condition. J. Exp. Mar. Biol. Ecol., 237: 61-73.

LAMBERT, Y., and J. D. DUTIL. 2000. Energetic consequences of reproduction in Atlantic cod (Gadus morhua) in relation to spawning level of somatic energy reserves. Can. J. Fish. Aquat. Sci., 57: 815-825.

LAMBERT, Y., N. A. YARAGINA, G. KRAUS, G. MARTEINSDOTTIR, and P. J. WRIGHT. 2003. Using environmental and biological indices as proxies of egg and larval production of marine fish. J. Northw. Atl. Fish. Sci., 33: 115-159 (this volume).

LAROCQUE, R. 2000. A SCUBA technique for collecting live Sebastes spp. specimens. Can. Tech. Rep. Fish. Aquat. Sci., 2309: 13 p.

LARSSON, D. G. J., C. C. MYLONAS, Y. ZOHAR, and L. W. CRIM. 1997. Gonadotropin-releasing hormone analogue (GnRH-A) induces multiple ovulations of highquality eggs in a cold-water, batch-spawning teleost, the yellowtail flounder (Pleuronectes ferrugineus). Can. J. Fish. Aquat. Sci., 54: 1957-1964.

LAUREL, B. J., J. A. BROWN, and R. ANDERSON. 2001. Behaviour, growth and survival of redfish larvae in relation to prey availability. J. Fish Biol., 59: 884-901.

LITVAK, M. K. 1999. The development of winter flounder (Pleuronectes americanus) for aquaculture in Atlantic Canada: current status and future prospects. Aquaculture, 176: 55-64.

MA, Y., O. S. KJESBU, and T. JØRGENSEN. 1998. Effects of ration on the maturation and fecundity in captive Atlantic herring (Clupea harengus). Can. J. Fish. Aquat. Sci., 55: 900-908.

MANNING, A. J., and L. W. CRIM. 1998. Maternal and interannual comparison of the ovulatory periodicity, egg production and egg quality of the batch-spawning yellowtail flounder. J. Fish. Biol., 53: 954-972.

MARTEINSDOTTIR, G., and A. STEINARSSON. 1998. Maternal influence on the size and viability of Iceland cod Gadus morhua eggs and larvae. J. Fish Biol., 52: 1241-1258.

MARTIN-ROBICHAUD, D. J., and M. A. ROMMENS. 2001. Assessment of sex and evaluation of ovarian maturation of fish using ultrasonagraphy. Aquacult. Res., 32: $113-120$.

MATTSON, N. S. 1991. A new method to determine sex and gonad size in live fishes by using ultrasonography. 
J. Fish. Biol., 39: 673-677.

MCEVOY (BARTON), L.-A. 1984. Ovulatory rhythms and over-ripening of eggs in cultivated turbot, Scophthalmus maximus L. J. Fish. Biol., 24: 437-448.

MCEVOY, L. A., and J. MCEVOY. 1992. Multiple spawning in several commercial fish species and its consequences for fisheries management, cultivation and experimentation. J. Fish. Biol., 41: 125-136.

MORGAN, J. D., and G. K. IWAMA. 1997. Measurements of stressed states in the field. In: Fish stress and health in aquaculture. G. K. Iwama, A.. D. Pickering, J. P. Sumpter and C. B. Schreck (eds.). Cambridge University Press, Cambridge, UK, p. 247-268.

MORGAN, M. J., C. E. WILSON, and L. W. CRIM. 1999. The effect of stress on reproduction in Atlantic cod. J. Fish Biol., 54: 477-488.

MURUA, H., and F. SABORIDO-REY. 2003. Female reproductive strategies of marine fish species of the North Atlantic. J. Northw. Atl. Fish. Sci., 33: 23-31(this volume).

MURUA, H., G. KRAUS, F. SABORIDO-REY, P. R. WITTHAMES, A. THORSEN, and S. JUNQUERA. 2003. Procedures to estimate fecundity of marine fish species in relation to their reproductive strategy. J. Northw. Atl. Fish. Sci., 33: 33-54 (this volume).

NAGLER, J. J., B. A. ADAMS, and D. G. CYR. 1999. Egg production, fertility, and hatch success of American plaice held in captivity. Trans. Am. Fish. Soc., 128: 727-736.

NISSLING, A., R. LARSSON, L. VALLIN, and K. FROHLUND. 1998. Assessment of egg and larval viability in cod, Gadus morhua: methods and results from an experimental study. Fish. Res., 38: 169-186.

NORBERG, B., V. VALKNER, J. HUSE, I. KARLSEN, and G. LEROEY GRUNG. 1991. Ovulatory rhythms and egg viability in the Atlantic halibut (Hippoglossus hippoglossus). Aquaculture, 97: 365-371.

OUELLET, P., Y. LAMBERT, and I. BÉRUBÉ. 2001. Cod egg characteristics and viability in relation to low temperature and maternal nutritional condition. ICES J. Mar. Sci., 58: 672-686.

PANKHURST, N. W., and G. VAN DER KRAAK. 1997. Effects of stress on reproduction and growth of fish. In: Fish stress and health in aquaculture. G. K. Iwama, A. D. Pickering, J. P. Sumpter and C. B. Schreck (eds.). Cambridge University Press, Cambridge, UK, p. 73-93.

PEPIN, P., D. C. ORR, and J. T. ANDERSON. 1997. Time to hatch and larval size in relation to temperature and egg size in Atlantic cod (Gadus morhua). Can. J. Fish. Aquat. Sci., 54(Suppl. 1): 2-10.

POTTINGER, T. G., and A. D. PICKERING. 1997. Genetic basis to the stress response: Selective breeding for stress-tolerant fish. In: Fish stress and health in aquaculture. G. K. Iwama, A. D. Pickering, J. P. Sumpter and C. B. Schreck (eds.). Cambridge University Press, Cambridge, UK, p. 171-193.

RIDEOUT, R. M., M. P. M. BURTON, and G. A. ROSE. 2000. Observations on mass atresia and skipped spawning in northern Atlantic cod, from Smith Sound, Newfoundland. J. Fish. Biol., 57: 1429-1440.

RIVEIRO, I., C. GUISANDE, M. LLOVES, I. MANEIRO, and J. M. CABANAS. 2000. Importance of parental effects on larval survival in Sardina pilchardus. Mar. Ecol. Prog. Ser., 205: 249-258.

SMITH, T. I. J., D. C. MCVEY, W. E. JENKINS, M. R. DENSON, L. D. HEYWARD, C. V. SULLIVAN, and D. L. BERLINSKY. 1999. Broodstock management and spawning of southern flounder, Paralichthys lethostigma. Aquaculture, 176: 87-99.

SVÅSAND, T., K. E. JÖRSTAD, H. OTTERÅ, and O. S. KJESBU. 1996. Differences in growth performance between Arcto-Norwegian and Norwegian coastal cod reared under identical conditions. J. Fish Biol., 49: 108-119.

THORSEN, A. and O. S. KJESBU. 2001. A rapid method for estimation of oocyte size and potential fecundity in Atlantic cod using a computer-aided particle analysis system. J. Sea Res., 46: 295-308.

THORSEN, A, E. A. TRIPPEL, and Y. LAMBERT. 2003. Experimental methods to monitor the production and quality of eggs of captive marine fish. J. Northw. Atl. Fish. Sci., 33: 55-70 (this volume).

TRIPPEL, E. A. 1998. Egg size and viability and seasonal offspring production of young Atlantic cod. Trans. Am. Fish. Soc., 127: 339-359.

TRIPPEL, E. A., C. M. DOHERTY, J., WADE, and P. R. HARMON. 1998. Controlled breeding technology for haddock (Melanogrammus aeglefinus) in mated pairs. Bull. Aquacul. Assoc. Can., 98-3: 30-35.

WATANABE, W. O., P. M. CARROLL, and H. V. DANIELS. 2001. Sustained, natural spawning of southern flounder Paralichthys lethostigma under an extended photothermal regime. J. World Aquacult. Soc., 32: $153-166$.

WITTHAMES, P. R., T. E. ANDERSEN, and O. S. KJESBU. MS 2000. The application of tank experiments to the study of reproductive potential in teleosts using Gadus morhua as a test model. ICES C.M. Doc., No. 2000/ $\mathrm{R}: 09$.

WITTHAMES, P. R., and M. G. WALKER. 1995. Determination of fecundity and oocyte atresia in sole (Solea solea) from the Channel, the North Sea and the Irish Sea. Aquat. Living Resour., 8: 91-109.

YAMADA, J., and M. KUSAKARI. 1991. Staging and the time course of embryonic development in kurosoi, Sebastes schlegeli. Environ. Biol. Fish., 30: 103-110. 